\title{
Relationship between growth velocity and change of levels of insulin-like growth factor-1, insulin-like growth factor binding protein-3 and, IGFBP-3 promoter polymorphism during GnRH agonist treatment
}

Jun-Hong Park, MD', Il-Tae Hwang, MD, PhD', Seung Yang, $\mathrm{MD}, \mathrm{PhD}^{2}$

'Department of Pediatrics, Kangdong Sacred Heart Hospital, Seoul, Korea ${ }^{2}$ Department of Pediatrics, Hanyang University Guri Hospital, Guri, Korea
Received: 23 January, 2020

Revised: 26 March, 2020

Accepted: 20 July, 2020

\section{Address for correspondence:}

Seung Yang, MD, PhD

Department of Pediatrics, Hanyang University Guri Hospital, 153, Gyeongchun-ro, Guri 11923, Korea

Tel: +82-31-560-2251

Fax: +82-31-560-2786

E-mail: jxisfriend@gmail.com

https://orcid.org/0000-0002-33806962
Purpose: This study aims to investigate the effect of gonadotropin-releasing hormone agonist (GnRHa) on the growth hormone (GH)-insulin-like growth factor-1 (IGF-1) axis and to evaluate whether -202 A/C IGF binding protein-3 (IGFBP-3) promoter polymorphism affects growth velocity in females with central precocious puberty (CPP) during treatment.

Methods: Data was collected from 97 females younger than 9 years, diagnosed with precocious puberty and treated with GnRHa for at least 1 year at Kangdong Sacred Heart Hospital from 2014 to 2015. Their body height, weight, change in height standard deviation score ( $\triangle \mathrm{SDS}$ ), serum IGF-1, serum IGFBP-3, bone age, and -202 A/C IGFBP-3 promoter polymorphism were measured before and after $\mathrm{GnRHa}$ treatment. The interrelationships between the variables were calculated.

Results: During treatment, height SDS, IGF-1 SDS, IGFBP-3 SDS, and IGF-1/IGFBP-3 ratio significantly decreased. A significant correlation was observed between $\triangle \mathrm{IGF}-1$ SDS and $\Delta$ height SDS $(r=0.405, P<0.001)$. The presence of the $C$ allele was significantly correlated with IGF-1 SDS after treatment $(P=0.049)$ and with IGFBP-3 SDS before and after treatment $(P=0.012$ and $P=0.001)$, but not with $\triangle I G F-1$ SDS, $\triangle$ IGFBP-3 SDS, $\triangle$ IGF-1/IGFBP-3 ratio, or $\triangle$ height SDS.

Conclusion: Growth velocity during GnRHa treatment is related to $\triangle \mathrm{IGF}-1 \mathrm{SDS}$, indicating the apparent impact of GnRHa on the GH-IGF-1 axis. The -202 A/C IGFBP-3 promoter polymorphism does not affect the growth velocity of $\mathrm{GnRHa}$ in CPP girls.

Keywords: Precocious puberty, Growth velocity, Insulin-like growth factor-1, Insulinlike growth factor binding protein-3,-202 A/C IGFBP-3, Promoter regions

\section{Introduction}

When females and males younger than 8 and 9 years, respectively, undergo secondary sexual changes caused by stimulation of the hypothalamic-pituitary-gonadal axis, they are diagnosed with central precocious puberty $(\mathrm{CPP}){ }^{1)}$ A recent study reported an increasing number of CPP patients in South Korea from 2008 to $2014{ }^{2)}$ Concerns regarding the negative effects of $\mathrm{CPP}$ are increasing, one of which includes reduced stature caused by accelerated early growth and bone maturation.

Gonadotropin-releasing hormone agonist (GnRHa) is the treatment of choice in CPP patients because it increases final adult height by reducing progression of bone age (BA) and extending the duration of growth. ${ }^{4)}$ GnRHa induces downregulation of the hormonal axis and decreases the production of luteinizing hormone $(\mathrm{LH})$ and follicle-stimulating hormone, 
resulting in gonadal suppression. These sex hormones are responsible for early bone maturation and pubertal growth spurts. Therefore, gonadal suppression delays bone maturation and growth velocity to those of prepuberty levels. ${ }^{5}$

Multiple factors such as initial chronological age (CA), initial height, target height, and BA advancement affect the treatment response and final height. ${ }^{6-8)} \mathrm{GnRHa}$ treatment increases serum growth hormone-binding protein concentration and decreases serum IGF-I and IGFBP-3 concentrations. ${ }^{9}$ However, predicting final height remains a challenge due to the variable factors affecting the treatment outcome and the course of precocious puberty.

Other genetic components are presumed to influence the competence of GnRHa. Specifically, -202 A/C IGFBP-3 promoter polymorphism is associated with increased IGFBP-3 level and growth velocity during growth hormone $(\mathrm{GH})$ treatment for prepubertal GH deficiency. ${ }^{10,11)}$ Another study revealed the effect of $-202 \mathrm{~A} / \mathrm{C}$ IGFBP-3 promoter polymorphism on the physical development of Korean females. However, its effect was unclear. ${ }^{12)}$

The present study was performed to clarify the effect of GnRHa on the GH-IGF-1 axis and to evaluate the predictive role of -202 A/C IGFBP-3 promoter polymorphism on growth velocity during $\mathrm{GnRHa}$ administration in females diagnosed with CPP.

\section{Materials and methods}

\section{Patients}

This study enrolled 97 young female subjects between the ages of 6 and 8 years who were diagnosed with CPP and administered GnRHa at Kangdong Sacred Heart Hospital, Seoul, Korea, from January 2014 to January 2015. The subjects were diagnosed with CPP when they presented with breast budding above Tanner stage $\mathrm{B} 2$ before 8 years of $\mathrm{CA}$, revealed $\mathrm{BA}$ advancement of more than one year compared to $\mathrm{CA}$, and had $5 \mathrm{IU} / \mathrm{L}$ or greater peak LH level after the gonadotropin releasing hormone stimulation test. In total, 22 subjects who were diagnosed with hypothyroidism, GH deficiency, or congenital adrenal hyperplasia or who underwent previous $\mathrm{GH}$ treatment or were born small for gestational age were excluded. GnRHa was injected every 4 weeks. Children weighing more than $30 \mathrm{~kg}$ were injected with $3.75 \mathrm{mg}$ of GnRHa, compared to $2.5 \mathrm{mg}$ for those below $30 \mathrm{~kg}$.

\section{Measurements}

Body height and weight, serum IGF-1 and IGFBP-3 concentrations, and the BA of patients were measured before and one year after GnRHa treatment. A Harpenden Stadiometer (Holtain Ltd., Pembs. UK) was used to approximate height to the closest 0.1 . Thereafter, body mass index (BMI) was calculated as weight in kilograms divided by height in meters squared. Midparental height (MPH) was calculated by adding the height of the parents, subtracting 13 , and dividing by 2 . An IGF-1-D-RIA-CT kit (Biosource, Nivelles, Belgium) was utilized to measure serum IGF-1 concentration through the radioimmune method, whereas an immunoradiometric assay with Immunotech IRMA IGFBP-3 kit (Immunotech, Marseile, France) was used to evaluate the serum IGFBP-3 concentration. BA was based on left hand anteroposterior radiographs, and the measurements were performed in accordance with the Greulich and Pyle Atlas. ${ }^{13)}$

\section{Molecular study}

Genomic DNA was extracted from patient blood samples. The target IGFBP-3 gene containing $-202 \mathrm{~A} / \mathrm{C}$ polymorphic sites of 459 base pairs (bp) at the promoter region was amplified using corresponding sense and antisense primers. The polymerase chain reaction (PCR) product was sheared using the Alw21I restriction enzyme (Thermo Scientific, Waltham, MA, USA) to verify the allele types through restriction fragment length polymorphism and agarose gel electrophoresis. The PCR product was digested into 242-bp and 162-bp fragments containing an A allele and into 288-bp and 162-bp fragments when a $C$ allele was present. ${ }^{14)}$

\section{Statistical analysis}

The definition of age-adjusted height velocity was established according to the difference between initial height SDS and final height SDS to minimize the confounding effect of age. Height SDS was calculated using Cole's modified least mean squares (LMS) algorithm. ${ }^{15)}$ The LMS values were provided by the 2007 version of Korean National Growth Charts for Children and Adolescents. ${ }^{16)}$ For IGF-I and IGFBP-3 SDSs, the LevenbergMarquardt algorithm was used to estimate the parameters from percentile values in Korean females. ${ }^{16,17)}$ Changes of IGF1 and IGFBP-3 SDSs after GnRHa treatment were calculated and expressed as $\triangle$ SDS. The molar ratio of IGF- 1 and IGFBP-3 was calculated, and the ratio of IGF-1/IGFBP- 3 after treatment over the initial value was calculated and expressed as $\triangle \mathrm{IGF}-1 /$ IGFBP-3 ratio.

The mean, SDS, minimum, and maximum values of the continuous data were obtained by descriptive statistics and compared for statistical significance using paired t-test before and after treatment. Pearson correlation analysis evaluated the association between $\triangle$ height SDS and parameters of BMI, initial height SDS, MPH, BA advancement, and $\triangle \mathrm{IGF}-1$ SDS, $\triangle \mathrm{IGFBP}-3$ SDS, and $\triangle \mathrm{IGF}-1 / \mathrm{IGFBP}-3$ ratio. Univariate and multivariate regression analyses were performed to investigate the effects of $\Delta \mathrm{IGF}-1$ SDS, $\triangle \mathrm{IGFBP}-3$ SDS, and $\Delta \mathrm{IGF}-1 /$ IGFBP-3 ratio on $\triangle$ Height SDS. All covariates associated with the height velocity from the Pearson correlation analysis adjusted for initial height SDS, $\triangle \mathrm{IGF}-1$ SDS, $\triangle \mathrm{IGFBP}-3$ SDS, and $\triangle$ IGF-1/IGFBP-3 ratio 
The target patients were arranged into 2 subgroups based on the allele of -202 A/C IGFBP-3 promoter polymorphism. Independent $t$-test was performed between the 2 subgroups for SDS values of height, IGF-1, IGFBP-3, and IGF-1/IGFBP-3 before and after treatment. $\triangle \mathrm{IGF}-1$ SDS, $\triangle \mathrm{IGFBP}-3 \mathrm{SDS}, \triangle \mathrm{IGF}-$ $1 /$ IGFBP- 3 ratio, and $\Delta$ height SDS were compared between the 2 subgroups. The differences of IGF-1 SDS and IGFBP-3 SDS before and after GnRHa treatment within the subgroups were confirmed by paired $t$-test.

All statistical analyses were performed with IBM SPSS Statistics ver. 26.0 (IBM Co., Armonk, NY, USA). A value of $P<0.05$ was considered statistically significant.

\section{Results}

Mean values of CA, BA, MPH, height SDS, and BMI before treatment were $8.5 \pm 0.5$ years, $10.5 \pm 0.6$ years, $160.0 \pm 3.2 \mathrm{~cm}$, $1.2 \pm 0.8$, and $18.2 \pm 2.4$, respectively. The SDSs for serum IGF1 and IGFBP- 3 concentrations were $0.8 \pm 1.0$ and $3.3 \pm 1.1$, respectively, and the IGF-1/IGFBP- 3 ratio was $60.7 \pm 16.3$. Subsequently, the mean BA value after one year of treatment was $10.9 \pm 0.6$ years. The difference between BA and CA was significantly reduced from $2.0 \pm 0.6$ to $1.3 \pm 0.6(P<0.001)$ and the height SDS to $1.1 \pm 0.8(P<0.001)$ after GnRHa. SDSs of serum IGF-1 and IGFBP-3 concentrations significantly decreased to $0.5 \pm 0.9(P<0.001)$ and $2.3 \pm 0.9(P<0.001)$, respectively. However there was no significant change in IGF-1/IGFBP-3 ratio after treatment $(P=0.887)$ (Table 1$)$.

$\triangle \mathrm{IGF}-1$ SDS $(r=0.405, P<0.001), \Delta \mathrm{IGFBP}-3$ SDS $(r=0.228$, $P=0.025)$, and $\Delta$ serum IGF- $1 /$ IGFBP- 3 ratio $(r=0.204, P=0.045)$ showed significant positive correlations with $\Delta$ height SDS. On the other hand, initial height SDS was negatively correlated with $\Delta$ height SDS $(r=-0.307, P=0.002)$. Correlation analysis between $\triangle$ Height SDS, BMI, MPH, and BA advancement showed no statistical significance (Table 2). Only $\triangle \mathrm{IGF}-1$ SDS was significantly related to $\triangle$ height SDS on multivariate regression analysis after adjusting for covariates of $\triangle \mathrm{IGF}-1 \mathrm{SDS}, \triangle \mathrm{IGFBP}-3$

Table 1. Characteristics of the $\mathbf{9 7}$ girls treated with GnRHa

\begin{tabular}{lcccc}
\hline Characteristic & At diagnosis & After a year & Post-Pre & P-value \\
\hline CA (yr) & $8.5 \pm 0.5$ & $9.6 \pm 0.5$ & - & - \\
BA (yr) & $10.5 \pm 0.6$ & $10.9 \pm 0.6$ & $0.4 \pm 0.4$ & $<0.001$ \\
BA-CA (yr) & $2.0 \pm 0.6$ & $1.3 \pm 0.6$ & $-0.6 \pm 0.4$ & $<0.001$ \\
Height SDS & $1.2 \pm 0.8$ & $1.1 \pm 0.8$ & $-0.1 \pm 0.2$ & $<0.001$ \\
BMI & $18.2 \pm 2.4$ & $19.3 \pm 2.7$ & $1.1 \pm 0.9$ & $<0.001$ \\
IGF-1 SDS & $0.8 \pm 1.0$ & $0.5 \pm 0.9$ & $-0.3 \pm 0.7$ & $<0.001$ \\
IGFBP-3 SDS & $3.3 \pm 1.1$ & $2.3 \pm 0.9$ & $-1.0 \pm 1.0$ & $<0.001$ \\
IGF-1/IGFBP-3 & $60.7 \pm 16.3$ & $60.5 \pm 16.8$ & $-0.2 \pm 14.4$ & 0.887 \\
Midparental height $(\mathrm{cm})$ & $160.0 \pm 3.2$ & - & - & -
\end{tabular}

Values are presented as mean \pm standard deviation.

GnRHa, gonadotropin-releasing hormone agonist; CA, chronological age; BA, bone age; SDS, standard deviation score; BMI, body mass index; IGF-1, insulin like growth factor 1; IGFBP-3, insulinlike growth factor binding protein 3 .

${ }^{*} P<0.05$ compared before and after the treatment.
SDS, $\triangle \mathrm{IGF}-1 / \mathrm{IGFBP}-3$ ratio, and initial height SDS $(\beta=0.110$, $P \leq 0.001$ ) (Table 3).

According to the $-202 \mathrm{~A} / \mathrm{C}$ IGFBP-3 promoter polymorphism analyses, 72 AA genotypes (74.2\%), 22 AC genotypes (22.7\%), and $3 \mathrm{CC}$ genotypes $(3.1 \%)$ were present. The $\mathrm{C}$ allele frequency accounted for $14.4 \%$ of the study population. These genotypes were divided into 2 subgroups based on $\mathrm{C}$ allele presence. No significant difference was observed in IGF-1 SDS before treatment between the 2 subgroups $(P=0.421)$. However, the group with the $\mathrm{C}$ allele exhibited notably lower IGF-1 SDS after treatment $(P=0.049)$. IGFBP-3 SDS was lower in the $\mathrm{C}$ allele groups both before and after GnRHa treatment $(P=0.012$ and $P=0.001$, respectively). Height SDS IGF-1/IGFBP- 3 ratio, $\triangle$ IGF1 SDS, $\triangle$ IGFBP- 3 SDS, $\triangle$ IGF-1/IGFBP- 3 ratio, and $\Delta$ height SDS between the 2 subgroups exhibited no significant differences before and after treatment (Supplementary Table 1). There were significant changes of IGF-1 SDS after GnRHa treatment within both subgroups ( $P=0.005$ and $P<0.001$, respectively) (Fig. 1A). IGFBP-3 SDS also significantly decreased in both subgroups $(P<0.001$ and $P<0.001$, respectively) (Fig. 1B).

\section{Discussion}

The GH-IGF axis directly or indirectly influences skeletal development, especially during puberty. However, the mecha-

\section{Table 2. Pearson correlation analysis}

\begin{tabular}{lc}
\hline Variable & $\Delta$ Height SDS \\
\hline Body mass index & $0.035(0.736)$ \\
Initial height SDS & $-0.307^{*}(0.002)$ \\
Midparental height & $-0.109(0.288)$ \\
BA advancement & $-0.017(0.871)$ \\
$\triangle I G F-1$ SDS & $0.405^{*}(<0.001)$ \\
$\triangle I G F B P-3$ SDS & $0.228^{*}(0.025)$ \\
$\triangle I$ GF-1/IGFBP-3 ratio & $0.204^{*}(0.045)$ \\
\hline
\end{tabular}

Values are presented as correlation coefficient $r$ ( $P$-value). SDS, standard deviation score; BA, bone age; IGF-1, insulin like growth factor 1 ; IGFBP-3, insulin-like growth factor binding protein 3.

${ }^{*} P<0.05$.

Table 3. Univariate and multivariate regression model to find factors associated with $\Delta$ height SDS

\begin{tabular}{lccccc}
\hline \multirow{2}{*}{ Variable } & \multicolumn{4}{c}{$\Delta$ Height SDS } \\
\cline { 2 - 3 } & \multicolumn{2}{c}{ Univariate analysis } & & Multivariate analysis \\
\cline { 2 - 3 } \cline { 5 - 6 } & $\beta \pm$ SE & $P$-value & $\beta \pm$ SE & $P$-value \\
\hline DIGF-1 SDS & $0.110 \pm 0.025$ & $<0.001$ & $0.110 \pm 0.025$ & $<0.001$ \\
DIGFBP-3 SDS & $0.041 \pm 0.018$ & 0.025 & - & 0.429 \\
DIGF-1/IGFBP-3 ratio & $0.147 \pm 0.072$ & 0.045 & - & 0.271 \\
Initial height SDS & $-0.069 \pm 0.022$ & 0.002 & - & 0.099 \\
\hline
\end{tabular}

Values are presented as regression coefficient ( $\beta) \pm$ standard error (SE).

SDS, standard deviation score; IGF-1, insulin like growth factor 1; IGFBP-3, insulin-like growth factor binding protein 3.

" $P<0.05$. 

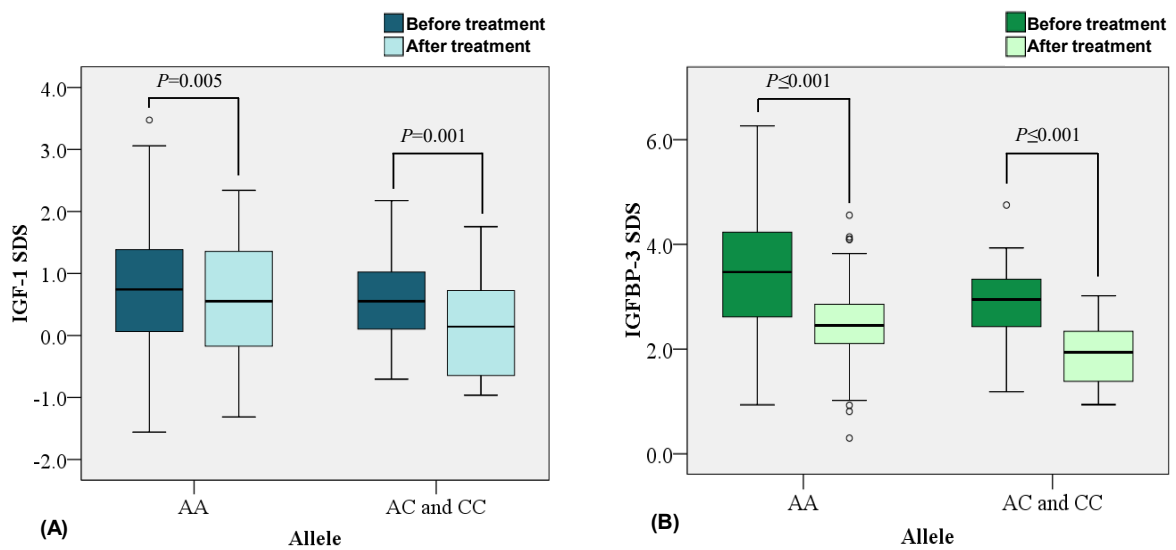

Fig. 1. The graphs resemble the differences of IGF-1 SDS (A) and IGFBP-3 SDS (B) before and after GnRHa treatment within the two allele subgroups. GnRHa, gonadotropin-releasing hormone agonist; SDS, standard deviation score; IGF-1, insulin like growth factor 1; IGFBP-3, insulin-like growth factor binding protein 3 .

nism of IGF-1 or IGFBP-3 action during puberty and how the hormones interact with each other remain unclear. Juul et al. ${ }^{18)}$ discovered that the increase of free IGF- 1 in puberty is not directly influenced by IGFBP-3 proteolysis. Verrotti et al. ${ }^{19)}$ compared the IGF-1 and IGFBP-3 concentrations between the 2 treatment regimens of GnRHa with or without cyproterone acetate and concluded that IGF- 1 and IGFBP-3 are regulated by different metabolic pathways.

Despite continuous attempts to effectively understand GnRHa action upon the GH-IGF-1 axis, studies have reported disparate results. Numerous previous studies have presented trivial changes in serum IGF-1 or IGFBP-3 level during GnRHa treatment in CPP patients, ${ }^{20-23)}$ in contrast to other studies where IGF-1 concentration decreased. ${ }^{9,18)}$ The present study aimed for a well-controlled project design to revise the GnRHa effect on the GH-IGF-1 axis and its relationship with height change. IGF-1 SDS and IGFBP-3 SDS decreased after 1 year of GnRHa treatment. However, after analyzing $\triangle \mathrm{IGF}-1$ SDS, $\triangle \mathrm{IGFBP}-3$ SDS, and $\Delta$ IGF- $1 /$ IGFBP- 3 ratio with $\Delta$ Height SDS, only $\Delta \mathrm{IGF}$ 1 SDS was significantly related. This result supports that IGF1 plays a major role in pubertal height gain, and that a decrease in IGF-1 during GnRHa treatment restores the growth velocity to that before puberty. Among the numerous characteristics that increase final adult height in treated CPP patients, other than the GH-IFG-1 axis, ${ }^{6-8)}$ we reevaluated BA advancement, initial height SDS, BMI, and MPH to determine whether they influenced growth velocity during GnRHa treatment. However, none were statistically associated with $\triangle$ Height SDS, suggesting that it is inappropriate to predict final adult height in CPP females based on $\mathrm{BA}$, body figure, or parental height.

The - 202 A/C IGFBP-3 promoter polymorphism has been suggested to be a potential genetic determinant that alters the GH-IGF-1 axis. Studies have reported that the presence of the $\mathrm{C}$ allele genotype is associated with low serum IGFBP level. ${ }^{24-26)}$ Since IGFBP has a role in pubertal growth, there is a potential for -202 A/C IGFBP-3 promoter polymorphism to affect growth velocity and final adult height. Nevertheless, it was difficult to confirm a concrete correlation due to the discrete results. According to Miletta et al. ${ }^{27}$ the IGFBP-3 genotype had no effect on final height after GH treatment in severe GHD patients. In contrast, Costalonga et al. ${ }^{10)}$ implied that the -202 A allele polymorphism of the IGFBP-3 promoter region was associated with not only higher IGFBP-3 levels, but also increased growth during recombinant human GH treatment in prepubertal GHD children.

This study focused on the effect of the -202 A/C IGFBP-3 promoter polymorphism on the GH-IGF-1 axis as well as the growth velocity in CPP females undergoing GnRHa treatment for at least 1 year. We compared SDS of IGF- 1 and IGFBP-3 between the 2 subgroups before and after GnRHa treatment. The results showed that IGF-1 SDS was not statistically different before treatment, but the group with the $\mathrm{C}$ allele after treatment demonstrated lower IGF-1 SDS than the AA subgroup. The IGFBP-3 SDS was lower in the C allele subgroup both before and after GnRHa treatment. However, change of IGF-1 SDS, IGFBP-3 SDS, or IGF-1/IGFBP-3 during treatment exhibited no significant difference between the 2 subgroups. Divergence of age-adjusted height velocity between the 2 allele groups was trivial. The effect of GnRHa on IGF-1 SDS or IGFBP-3 SDS was noted in both subgroups, regardless of allele. This suggests that $-202 \mathrm{~A} / \mathrm{C}$ IGFBP-3 promoter polymorphism does not significantly affect the therapeutic effect of GnRHa in CPP females.

Our study was carefully designed with a uniform diagnosis and treatment protocol in which GnRHa was administered every 4 weeks to all enrolled CPP patients. Target patients with the $\mathrm{C}$ allele alone could not substantially contribute to a definitive conclusion due to the small number. Therefore, children with CC and AC genotypes of -202 A/C IGFBP-3 promoter polymorphism were pooled into a single subgroup. This is due to a racial characteristic that the Korean population has a higher proportion of the A allele compared to other 
populations. ${ }^{12,25,28)}$ Another limitation of our study is that free IGF-1 level was estimated using the IGF-1/IGFBP- 3 ratio. This estimation, however, is based on a previous study conducted by Juul et al. ${ }^{18)}$ showing that free IGF-1 concentration significantly correlates with the molar ratio of IGF-1 and IGFBP-3.

In conclusion, growth velocity during $\mathrm{GnRHa}$ treatment is related to $\triangle \mathrm{IGF}-1$ SDS, and GnRHa seems to have an impact on the GH-IGF-1 axis. The C allele in the -202 A/C IGFBP-3 promoter regions was not associated with the growth rate during GnRHa treatment in CPP girls and did not affect the reduction of IGF-1 SDS or IGFBP-3 SDS during treatment.

\section{Ethical statement}

The study was approved by the Institutional Review Board of Kangdong Sacred Heart Hospital (approval number: 2014-02003). Informed consent was obtained from the parents or legal guardians of the children.

\section{Conflict of interest}

No potential conflict of interest relevant to this article was reported.

\section{Acknowledgments}

This study was financially supported by a research grant from the Investigator-Initiated Trials program of Ferring Pharmaceuticals. Opinions expressed in this paper are those of the authors and do not necessarily represent those of Ferring Pharmaceuticals. The authors would thank Ferring Pharmaceuticals for supporting this research.

\section{Supplementary material}

Supplementary Table 1 can be found via https://doi.org/ apem.2040020.010.

\section{References}

1. Kliegman RM, Stanton B, St. Geme J, Schor N, Behrman RE. Nelson textbook of pediatrics. 20th ed. Philadelphia: Elsevier Saunders, 2019:2899-912.

2. Kim YJ, Kwon A, Jung MK, Kim KE, Suh J, Chae HW, et al. Incidence and prevalence of central precocious puberty in Korea: an epidemiologic study based on a national database. J Pediatr 2019;208:221-8.

3. Carel JC, Lahlou N, Roger M, Chaussain JL. Precocious puberty and statural growth. Hum Reprod Update 2004;10:135-47.

4. Adan L, Chemaitilly W, Trivin C, Brauner R. Factors predicting adult height in girls with idiopathic central precocious puberty: implications for treatment. Clin
Endocrinol 2002;56:297-302.

5. Attie KM, Ramirez NR, Conte FA, Kaplan SL, Grumbach MM. The pubertal growth spurt in eight patients with true precocious puberty and growth hormone deficiency: evidence for a direct role of sex steroids. J Clin Endocrinol Metab 1990;71:975-83.

6. Paul D, Conte FA, Grumbach MM, Kaplan SL. Long-term effect of gonadotropin-releasing hormone agonist therapy on final and near-final height in 26 children with true precocious puberty treated at a median age of less than 5 years. J Clin Endocrinol Metab 1995;80:546-51.

7. Allali S, Lemaire P, Couto-Silva AC, Prete G, Trivin C, Brauner R. Predicting the adult height of girls with central precocious puberty. Med Sci Monit 2011;17:PH41-8.

8. Kauli R, Galatzer A, Kornreich L, Lazar L, Pertzelan A, Laron Z. Final height of girls with central precocious puberty, untreated versus treated with cyproterone acetate or GnRH analogue. A comparative study with re-evaluation of predictions by the Bayley-Pinneau method. Horm Res 1997;47:54-61.

9. Antoniazzi F, Bertoldo F, Zamboni G, Valentini R, Sirpresi S, Cavallo L, et al. Bone mineral metabolism in girls with precocious puberty during gonadotrophinreleasing hormone agonist treatment. Eur J Endocrinol 1995; 133:412-7.

10. Costalonga EF, Antonini SR, Guerra-Junior G, Mendonca BB, Arnhold IJ, Jorge AA. The -202 A allele of insulinlike growth factor binding protein-3 (IGFBP3) promoter polymorphism is associated with higher IGFBP-3 serum levels and better growth response to growth hormone treatment in patients with severe growth hormone deficiency. J Clin Endocrinol Metab 2009;94:588-95.

11. Costalonga EF, Antonini SR, Guerra G Jr, Coletta RR, Franca MM, Braz AF, et al. Growth hormone pharmacogenetics: the interactive effect of a microsatellite in the IGF1 promoter region with the GHR-exon 3 and $-202 \mathrm{~A} / \mathrm{C}$ IGFBP3 variants on treatment outcomes of children with severe GH deficiency. Pharmacogenomics J 2012;12:43945.

12. Yi MJ, Park TY, Hwang IT, Yang S. Influence of the $-202 \mathrm{~A} /$ $\mathrm{C}$ insulin-like growth factor-binding protein-3 promoter polymorphism on individual variation in height in Korean girls. Ann Pediatr Endocrinol Metab 2017;22:36-42.

13. Greulich WW, Pyle SI. Radiographic atlas of skeletal development of the hand and wrist. 2nd ed. California: Stanford University Press, 1959:256.

14. Deal C, Ma J, Wilkin F, Paquette J, Rozen F, Ge B, et al. Novel promoter polymorphism in insulin-like growth factor-binding protein-3: correlation with serum levels and interaction with known regulators. J Clin Endocrinol Metab 2001;86:1274-80.

15. Cole TJ. The LMS method for constructing normalized growth standards. Eur J Clin Nutr 1990;44:45-60.

16. Moon JS, Lee SY, Nam CM, Choi JM, Choe BK, Seo JW, et al. 2007 Korean National Growth Charts: review of 
developmental process and an outlook. Clin Exp Pediatr 2008;51:1-25.

17. Hyun SE, Lee BC, Suh BK, Chung SC, Ko CW, Kim HS, et al. Reference values for serum levels of insulin-like growth factor-I and insulin-like growth factor binding protein-3 in Korean children and adolescents. Clin Biochem 2012;45:16-21.

18. Juul A, Flyvbjerg A, Frystyk J, Muller J, Skakkebaek NE. Serum concentrations of free and total insulin-like growth factor-I, IGF binding proteins -1 and -3 and IGFBP-3 protease activity in boys with normal or precocious puberty. Clin Endocrinol 1996;44:515-23.

19. Verrotti A, Ferrari M, Sabatino G, Morgese G, Chiarelli F. Serum insulin-like growth factor-I (IGF-I) and IGF binding protein-3 levels in children with precocious puberty treated with gonadotropin-releasing hormone analog without or in combination with cyproterone acetate. Gynecol Endocrinol 1997;11:243-50.

20. Kanety H, Karasik A, Pariente C, Kauschansky A. Insulinlike growth factor-I and IGF binding protein-3 remain high after GnRH analogue therapy in girls with central precocious puberty. Clin Endocrinol 1996;45:7-12.

21. Sklar CA, Rothenberg S, Blumberg D, Oberfield SE, Levine LS, David R. Suppression of the pituitary-gonadal axis in children with central precocious puberty: effects on growth, growth hormone, insulin-like growth factor-I, and prolactin secretion. J Clin Endocrinol Metab 1991;73:7348.

22. Cisternino M, Draghi M, Lauriola S, Scarcella D, Bernasconi S, Cavallo L, et al. The acid-labile subunit of human ternary insulin-like growth factor-binding protein complex in girls with central precocious puberty before and during gonadotropin-releasing hormone analog therapy. J Clin
Endocrinol Metab 2002;87:4629-33.

23. Song HS, Choi WB, Song JS, Hwang IT, Yang S. Relationship between serum insulin-like growth factor-1, IGF binding protein-3 levels and body height before and after gonadotropin-releasing hormone agonist therapy. Ann Pediatr Endocrinol Metab 2014;19:208-13.

24. van der Kaay DC, Hendriks AE, Ester WA, Leunissen RW, Willemsen RH, de Kort SW, et al. Genetic and epigenetic variability in the gene for IGFBP-3 (IGFBP3): correlation with serum IGFBP-3 levels and growth in short children born small for gestational age. Growth Horm IGF Res 2009;19:198-205.

25. Park K, Kim JH, Jeon HG, Byun SS, Lee E. Influence of IGFBP3 gene polymorphisms on IGFBP3 serum levels and the risk of prostate cancer in low-risk Korean men. Urology 2010;75:1516.e1-7.

26. Safarinejad MR, Shafiei N, Safarinejad S. Relationship of insulin-like growth factor (IGF) binding protein-3 (IGFBP-3) gene polymorphism with the susceptibility to development of prostate cancer and influence on serum levels of IGF-I, and IGFBP-3. Growth Horm IGF Res 2011;21:146-54.

27. Miletta MC, Scheidegger UA, Giordano M, Bozzola M, Pagani S, Bona G, et al. Association of the (CA)n repeat polymorphism of insulin-like growth factor-I and -202 A/C IGF-binding protein-3 promoter polymorphism with adult height in patients with severe growth hormone deficiency. Clin Endocrinol 2012;76:683-90.

28. Han SG, Park KH, Sung JS, Whang YM, Kim YJ, Shin ES, et al. Single nucleotide polymorphisms of IGFBP-3 gene and lung cancer risk in a Korean population. Lung Cancer 2008;62:152-61. 